\title{
Estudio jurídico sobre el Derecho al desarrollo de los pueblos; un acercamiento al Progreso Legal
}

Legal Study on the Right to Development of Peoples; an approach to Legal Progress

\author{
José Luis Rodríguez Araya \\ Recibido: 27/8/2015 / Aprobado: 12/4/2016
}

Resumen

\begin{abstract}
Este artículo aborda analíticamente el porqué el Derecho al Desarrollo es un Derecho Humano y como tal debe ser exigido por la ciudadanía, cuando se vea privada de política pública y planes estratégicos para alcanzar el Bienestar Social y la Justicia Social como nación o comunidad, a través de la interpretación de la Declaración de Derechos Humanos de 1948 y las Declaraciones del Desarrollo en lo Social de 1969 y 1986.
\end{abstract}

Palabras Claves: Derecho al Desarrollo, Derechos Humanos, Declaración, Generaciones de Derechos, Progreso.

\section{Abstract}

This article analyzes the Right to Development as a human right, and as such it must be demanded by public citizens, when they are deprived of public policies and strategic plans, in order to achieve social welfare and social justice as a nation or community through the interpretation of the Declaration of Human Rights of 1948 and the Statements of Social Development in 1969 and 1986.

Keywords: Right to Development, Human Rights, Declaration, Rights Generations, Progress

\section{Introducción}

El Derecho Internacional actualmente se desenvuelve a partir de los principios generales de la Organización de las Naciones Unidas (ONU), tal como lo son los Derechos Humanos. En este ámbito, según Esquivel Salaz (2009), estos "se refieren al conjunto de facultades e instituciones que en cada momento histórico, concretan las exigencias de la dignidad, la libertad y la igualdad de los seres humanos" (p. 39), los cuales garantizan a la persona un equilibrio mental y físico saludable, con las condiciones adecuadas para tomar sus propias elecciones sin afectar a los demás.
En este marco, los Derechos Humanos son vinculantes para los agentes del Derecho, ya que constitucionalmente cuando las leyes interactúan con estos derechos, se articulan con la Carta Magna, de manera que se constituyen ambos para efectos jurídicos en un solo cuerpo normativo, llamado Bloque de Constitucionalida . En este sentido, los Derechos Humanos no solo forman parte de la normativa nacional, sino que llegan a constituir mandatos supralegales para la Administración Pública, extendidos sobre los actos del Estado y cuya vigencia debe ser garantizada por parte del Sistema de Justicia.

\footnotetext{
${ }^{1}$ Estudiante en Derecho de la Universidad de Costa Rica y Bachiller Internacional. Sede de Occidente. Correo electrónico: jose_-1993@hotmail.com

${ }^{2}$ El Bloque de Constitucionalidad, de acuerdo con Castillo Padilla (2009), "hace alusión a la existencia de una serie de normas, que si bien no constituyen formalmente parte del articulado o texto constitucional, la propia Constitución remite a ellas, de forma expresa o implícita, como pautas o referentes normativos que sirven de parámetro para enjuiciar la validez constitucional de las leyes y demás normas jurídicas" (p. 449)
} 
La presente investigación abordará el tema del Derecho al Desarrollo para explorar su origen, su interacción con otras generaciones de derechos y los principios que lo conforman; con el fin de definir una aplicación de este a la luz de la Normativa de la ONU.

\section{El Derecho al Desarrollo y su génesis en la tercera Generación de Derechos Humanos.}

Históricamente, las luchas del Movimiento Constitucionalista al que se expuso Europa a partir de 1789, con el inicio de la Revolución Francesa, es el origen de las tres primeras generaciones de Derechos, donde "la primera generación contiene los derechos civiles y políticos, la segunda generación contiene los derechos económicos, sociales y culturales, y la tercera contienen los derechos de los pueblos." (Esquivel Salas, 2009: 48). El investigador Felipe Gómez Isa señala que el Derecho al Desarrollo es una configuración jurídica del Principio de Solidaridad Fraternité, constituyéndose en un Derecho de Tercera Generación ${ }^{3}$. Esta tesis interpreta el Derecho al Desarrollo conforme al pasado, donde el Principio de Solidaridad fundamenta la naturaleza de este derecho como parte de la Tercera Generación.

En este contexto académico, la Solidaridad es el principal componente del Derecho al Desarrollo, y se define en "asumir como propio el interés de un tercero, identificándose con él" (Fernández Segado, 2012, p. 139). Esta manifestación llega a reproducirse en el Estado Social de Derecho con la positivización en el ordenamiento jurídico del "valor" de la Justicia Social, y como consecuencia de una diversidad de políticas públicas enfocadas en mantener un equilibrio en el nivel de vida de los ciudadanos. Según Fernández Segado (2012) "la Solidaridad, conjuntamente con la libertad, la igualdad y la justicia, han venido a conformar la [...] tetralogía axiológica del Estado Social" (p.140), el cual en su dimensión territorial utiliza las herramientas del Derecho Público, interviene en la sociedad para corregir contrastes económicos, sociales y educativos. Es importante definir que el interés general fundado en la solidaridad depende de una aportación tributaria de los ciudadanos, donde el "pago de los impuestos" es una obligación que permite al Estado, teóricamente, fungir como una autoridad intermediaria, eficiente y promotora del Desarrollo, a partir de su superioridad en relación con los administradores.

Es irrefutable que la realidad política, social, cultural e incluso económica de los países usualmente genere distorsiones a la lógica del Principio de Solidaridad, lo cual impide la concretización de sus "fines ideales" y repercute en la voluntad de los habitantes de un país con respecto al apoyo del modelo. Sin embargo, sin la cooperación fiscal de los ciudadanos o con una sociedad políticamente individualista, no podría siquiera considerarse la existencia de algún desarrollo promovido por las esferas gubernamentales. Asimismo, el Principio de Solidaridad es inaplicable sin un Estado que goce de fuerza institucional, esto se refiere:

"a la capacidad de elaboración y ejecución de políticas y de promulgación de leyes; administración eficaz con la mínima burocracia; control del soborno, la corrupción y el cohecho; mantenimiento de un alto nivel de transparencia y rendición de cuentas en las instituciones públicas; y lo más importante, el cumplimiento de las leyes" (Fukuyama, 2004, p. 25).

\footnotetext{
${ }^{3}$ Felipe Gómez (Sf.) expone que derecho al desarrollo constituye un derecho de muy reciente aparición, dado que data de los años setenta, de la mano del surgimiento de los derechos humanos de la tercera generación, también denominados derechos de la solidaridad. Este derecho, junto con el derecho a la paz, el derecho al medio ambiente, el derecho a disfrutar del patrimonio común de la humanidad o el derecho a la asistencia humanitaria, cierra, por el momento, el proceso de evolución de los derechos humanos iniciado con la Revolución Francesa. (parra. 2)
} 
En este ámbito, sin mecanismos eficaces de evaluación y autocoerción, el Estado sería incapaz de realizar las tareas relacionadas con el Desarrollo.

En el ámbito internacional, el Principio de Solidaridad se traduce con mayor fuerza en la cooperación entre Estados para mejorar sus condiciones, por medio del Derecho Internacional o Comunitario, en este estadio se encuentran las Naciones Unidas posee organizaciones afiliadas como la Organización de las Naciones Unidas para la Alimentación y la Agricultura (FAO), la Organización de las Naciones Unidas para la Educación, la Ciencia y la Cultura (UNESCO), La Organización Mundial de la Salud (OMS) y el Programa de las Naciones Unidades para el desarrollo (PNUD), la cuales fueron creadas para fomentar el desarrollo .

\section{El Derecho al Desarrollo: características y aplicación conceptual.}

El Derecho al Desarrollo encierra el cumplimiento de las garantías esbozadas en la Declaración de 1948 por ser progresivo, en este contexto ningún derecho humano puede surgir si causa algún menoscabo a otros establecidos, es por ello que un Estado que omita darle vigencia a los Derechos humanos de primera y segunda generación no podrá otorgarles a sus ciudadanos un desarrollo humano digno.
Como derecho humano, el Derecho al Desarrollo es universal; se aplica sin discriminación, es imprescriptible; "no tiene un periodo de tiempo para hacerse valer, ni para perderse" (Esquivel Salas, 2009, p. 42), es irrenunciable, intransferible e inalienable, en razón de que no puede venderse.

Además el Derecho al Desarrollo no pierde valor ante las otras generaciones de Derechos, sino que a contrario sensu llega a complementar los demás Derechos Humanos, y fomenta la aplicación de políticas públicas para el acercamiento a un "progreso ideal".

No obstante, la concepción del Derecho al Desarrollo crea conflictos que no permiten la totalidad de su aplicación en la realidad, pues el objeto de estudio se basa en términos como "desarrollo"5 y "progreso" ${ }^{\prime}$, los cuales son proclives a la interpretación ideológica y transforman el objeto de estudio en un instituto flexible frente a cualquier argumento preconcebido que emerja con el fin de modificar su esencia en función de algún interés. Además, se nutre del ideal del "Progreso Constante o Perpetuo", el cual constituye un objetivo improbable en cuanto no se pueden conservar las condiciones sociales y ambientales adecuadas para mantener un crecimiento continuo.

Por lo anterior el agente del derecho tiene el deber de identificar las imprecisiones del lenguaje y a través del ejercicio de la hermenéutica aplicar las declaraciones en sus extremos posibles, para dar solución a los conflictos en cada caso en concreto.

\footnotetext{
${ }^{4}$ Estas organizaciones responden a una lógica de desarrollo, de acuerdo con Laura García Matamoros. (2007): En el contexto de las Naciones Unidas y sus objetivos relativos al desarrollo se observa cómo la Carta de la Organización le asigna la tarea de concretar la cooperación internacional, tendiente a resolver los problemas internacionales de orden económico, social, intelectual o humanitario y asegurar dentro de este fin el mejoramiento de los niveles de vida, el pleno empleo y las condiciones de progreso y desarrollo en el orden económico y social. Sobre estos principios se estructura toda la acción de Naciones Unidas en torno al derecho al desarrollo. (p. 239)

${ }^{5}$ El Desarrollo Humano se define como un principio por el cual corresponde dictar las normas que sirvan para proveer lo conducente al progreso económico con justicia social, a la productividad de la economía nacional, a la generación de empleo, a la formación profesional de las y los trabajadores, a la defensa del valor de la moneda, a la investigación y al desarrollo científico y tecnológico, su difusión y aprovechamiento, al crecimiento armónico de la Nación y al poblamiento de su territorio, tanto como promover políticas diferenciadas que tiendan a equilibrar el desigual desarrollo. (Goldstein, 2008, p. 216)
}

${ }^{6}$ El progreso se define como: “el Desarrollo de una civilización.” (García, 1991, p.842) 


\section{La Declaración de Derechos Humanos y las Declaraciones sobre el Progreso (1969 y 1986)}

La Declaración de Derechos Humanos de las Naciones Unidas (1948) es un cuerpo normativo protector de bienes jurídicos esenciales, los cuales cimentan la dinámica de la sociedad contemporánea. En esta los derechos humanos se vinculan unos con otros y cada nueva generación de prerrogativas surge de la realimentación entre hechos del pasado y necesidades actuales. En esta declaración, el "Derecho al Desarrollo" no está expreso, sino que surge a partir de su interpretación, donde esta incentiva la intervención del Estado en la sociedad para garantizar el progreso, ya que la satisfacción colectiva de los derechos sociales, culturales y económicos, "[...].mediante el esfuerzo nacional y la cooperación internacional, habida cuenta de la organización y los recursos de cada Estado [...]." (ONU, 1948, p. 35) promueve escenarios para el desarrollo. Por esa razón, un Estado que a través de políticas públicas garantice a los ciudadanos acceso a la alimentación, el vestido, la vivienda, la asistencia médica, la educación y al trabajo digno estará aplicando los artículos 22, 23, 24, 25, 26 y 27 de la Declaración de Derechos Humanos, y al mismo tiempo las premisas del Derecho al Desarrollo. Además la declaración expone en su artículo 28 que "Toda persona tiene derecho a que se establezca un orden social e internacional en el que los derechos y las libertades proclamados en esta declaración se hagan efectivos." (ONU, 1948, p. 36), este "orden social" es la manifestación tacita del Derecho al Desarrollo como derecho humano, ya que constituye la vinculación de la Declaración de 1948 y las de 1969 y 1986 al ser estas interrelacionadas, la tríada internacional del Derecho al Desarrollo.

El objeto de estudio se debe interpretar a partir de las prerrogativas expresas en las declaraciones de 1969 y 1986, pues presentan una gama de valores ya positivizados que conforman el desarrollo, como lo son la Participación, la justicia social, el uso de la propiedad colectiva, el respeto a la propiedad privada, la Familia, el comercio, el trabajo libre, la libertad de asociación, el sindicalismo, la cooperación internacional, la igualdad y la soberanía. En esta línea, ambos cuerpos comparten los mismos principios y sus premisas son complementarias entre sí a raíz de dos características esenciales, primero: el Principio de Progresividad de los Derechos Humanos no permite el retroceso de prerrogativas ya reconocidas; y segundo: la interpretación sistemática evidencia relaciones, entre la declaración de 1969 y 1986, lo cual se refleja en el artículo 8 de la Declaración del Derecho al Desarrollo (1986) donde se expone que:

"Los Estados deben adoptar, en el plano nacional, todas las medidas necesarias para la realización del derecho al desarrollo y garantizarán, entre otras cosas, la igualdad de oportunidades para todos en cuanto al acceso a los recursos básicos, la educación, los servicios de salud, los alimentos, la vivienda, el empleo y la justa distribución de los ingresos. [...]. Deben hacerse reformas económicas y sociales adecuadas con objeto de erradicar todas las injusticias sociales." (ONU, 1986, p. 198)

Este texto evoca los valores de la década del sesenta y se relaciona con los artículos 8, 10, 11, 12 y 13 de la declaración de 1969, por tanto el derecho al desarrollo se constituye de las correlaciones de ambas declaraciones, hace de estas un solo bloque de consulta para aplicar el derecho al desarrollo. Además, en la Declaración de 1969, se plasma el Derecho al Desarrollo Humano como un instrumento altamente vinculado con la Declaración de 1948, tal como lo expone en su artículo 2 "El progreso social y el desarrollo en lo social se fundan en el respeto de la dignidad y el valor de la persona humana y deben asegurar la promoción de los derechos humanos y la justicia social" (ONU, 1969, p. 58).

En el plano internacional, los principios que rigen esta materia se manifiestan mediante disposiciones reguladoras de las relaciones entre naciones, para que no afecten la soberanía e integridad entre los Estados. ${ }^{7}$ Asimismo, se busca protección a las riquezas de los territorios y la autonomía de 
planificación de los gobiernos cuando el derecho al desarrollo reconoce "El derecho y la responsabilidad de cada Estado y, en lo que les concierne, de cada nación y cada pueblo, de determinar libremente sus propios objetivos de desarrollo social [...]" (ONU, 1969, p. 58). En este ámbito, un tratado que permita la explotación de riquezas naturales irracional en tierras extranjeras sin responsabilidad no puede proceder de conformidad con los preceptos del derecho al desarrollo.

En síntesis, la Declaración del Derecho al Desarrollo de 1969 y 1986 forman un bloque unitario que protege los Derechos de Primera y Segunda Generación, pues brindan las pautas, fines y principios jurídicos obligatorios para el desarrollo.

\section{Aplicación del Derecho al Desarrollo desde el ámbito político e internacional.}

¿Cómo se aplica el derecho al Desarrollo de los Pueblos y quién se encarga de ello? El Derecho al Desarrollo de los Pueblos es aplicado desde la iniciativa política, donde su interpretación se configura conforme a los intereses predominantes y el enfoque del concepto de desarrollo asumido por la tendencia ideológica del momento, es por ello que los programas sobre este tema son cambiantes. Por ejemplo, en la década del setenta se promulgaron políticas de desarrollo focalizadas en el proteccionismo, el asistencialismo y el fomento de actividades económicas, tal como lo expone el plan de Estrategia Internacional del Desarrollo del Segundo Decenio de las Naciones Unidas.

"Se requiere, pues una estrategia global del desarrollo [...] en todas las esferas de la vida económica y social: en la industria y en la agricultura, en el comercio, en las finanzas, en el empleo, en la educación, en la salud, en la vivienda, en la ciencia y la tecnología." (ONU, 1970, p. 2).
El Informe de la Estrategia del Tercer Decenio de las Naciones Unidas, diez años después, varía el enfoque del problema, pues descarta el proteccionismo y otorga mayor énfasis al mercado, en este ámbito, los países se comprometieron "a procurar el establecimiento de un sistema de comercio abierto [...] a fomentar la liberalización del comercio y a promover los ajustes estructurales necesarios que faciliten la realización de la dinámica comparativa" (ONU, 1980, p. 117). Entonces, a partir de los primeros decenios se evidencian transformaciones en cuanto los medios, sin variar el fin mismo del Derecho al Desarrollo.

Asimismo, el Informe de Estrategia Internacional de Desarrollo del Cuarto Decenio de las Naciones Unidas del año 1990 demuestra esta tesis, al intensificar el modelo del tercer decenio y fortalecerlo mediante el Programa de Desarrollo de 1997, donde se argumenta que "El gran aumento del comercio y de las corrientes de capital, así como los avances tecnológicos, presentan nuevas oportunidades para el crecimiento de la economía mundial, especialmente en los países en desarrollo." (ONU, 1997, p. 3). Es en este escenario donde se desvirtúan los principios del Derecho humano al Desarrollo y se transforma en el Derecho al Desarrollo del Mercado a través de la ecuación: mercado $=$ desarrollo.

En este contexto se evidencia que la aplicación del Derecho al Desarrollo es una tarea política, por lo cual las formas de desarrollo son cambiantes y es aquí donde el agente de Derecho debe evaluar la validez de las formas y efectos de desarrollo conforme a los principios de las declaraciones expuesta en este trabajo.

\footnotetext{
${ }^{7}$ La declaración sobre el Derecho al Desarrollo aclara que "El derecho humano al desarrollo implica también la plena realización del derecho de los pueblos a la libre determinación, que incluye, con sujeción a las disposiciones pertinentes de ambos Pactos internacionales de derechos humanos, el ejercicio de su derecho inalienable a la plena soberanía sobre todas sus riquezas y recursos naturales."(1986, artículo 1)
} 


\section{Conclusión}

El Derecho al Desarrollo como derecho humano se sustenta en el artículo 28 de la Declaración de Derechos Humanos de 1948 y se motiva en las Declaraciones del Desarrollo de 1969 y 1986, por lo que se constituye esencialmente en un bloque de principios jurídicos supraconstitucionales vinculantes para las agendas políticas de desarrollo y cuyo fundamento es la Justicia Social. Sin duda alguna es un derecho colectivo y casuístico que puede ser exigido por uno o varios sujetos, el cual en sede judicial garantiza el respeto de los derechos humanos dentro de la planificación gubernamental, cuando esta sea impugnada en cuanto a su contenido o efectos. En este sentido, la ecuación política, mercado $=$ desarrollo perpetuo, es incongruente con el derecho al desarrollo, pues violenta sus principios, no corresponde con la realidad de la naturaleza de los recursos y el mercado no es idóneo para solucionar problemas sociales. El derecho al desarrollo no es solo mercado, sino un desarrollo de los pueblos con principios de dignidad humana que en última instancia se acerca a un progreso legal.

\section{Agradecimientos}

A los profesores Jorge Córdoba Ortega e Isabel Montero Mora y al estudiante de Historia Carlos Vargas Jiménez por sus valiosas observaciones para la realización de este escrito.

\section{Bibliografía}

Castillo Padilla, F. (2009). El Derecho Internacional de los Derechos Humanos como parámetro de Constitucionalidad. En Constitución y Justicia Constitucional (pp. 441-252). San José: Escuela Judicial.

Esquivel Salas, H. (2009). Los Derechos Fundamentales en las constituciones de Costa Rica. En 20 años de Justicia Constitucional (pp. 39-78). San José: UNED.

Fernández Segado, F. (2012). La Solidaridad como principio constitucional. Revista UNED Teoría y Realidad Constitucional, (30), 139-181.

Fukuyama, F. (2004). La construcción del Estado: Hacia un nuevo orden mundial en el siglo XXI. Barcelona: Ediciones B.

García Matamoros, L. (2007). El Derecho del Desarrollo como base para la construcción del Derecho al Desarrollo. Revista colombiana de Derecho Internacional, (9), 235-272.

García Pelayo, R. (1991). Pequeño Laurousse ilustrado. Mexico DF: Editorial de Periódicos S.C.L.

Goldstein, M. (2008). Diccionario Jurídico. Buenos Aires: Editorial Circulo Latino Austral S.A

Gómez Isa, F. (sf). El Derecho al Desarrollo como Derecho Humano, consulta hecha en http://observatoridesc.org/files/cap11.pdf, (30/05/14).

Declaración de las Naciones Unidas sobre el Progreso y el Desarrollo en lo Social. (1969). Disponible en http://daccess-dds ny.un.org/ doc/RESOLUTION/GEN/NR0/259/32/IMG/ NR025932.pdf?OpenElement (30/05/14) 
Declaración de las Naciones Unidas sobre el Derecho al Desarrollo. (1986). Disponible en http://daccess-dds-ny.un.org/doc/ RESOLUTION/GEN/NR0/502/78/IMG/ NR050278.pdf?OpenElement (30/05/14)

Declaración de los Derechos Humanos. Disponible en http://daccess-dds-ny.un.org/doc/ RESOLUTION/GEN/NR0/046/82/IMG/ NR004682.pdf?OpenElement (30/05/14)

Resolución (1970) A/RES/2626 (XXV): Estrategia Internacional del Desarrollo para el Segundo Decenio de las Naciones Unidas. Disponible en http://daccess-dds-ny.un.org/ doc/RESOLUTION/GEN/NR0/352/87/IMG/ NR035287.pdf?OpenElement (17/6/15)

Resolución (1980) A/RES/35/56: Estrategia Internacional del Desarrollo para el Tercer Decenio de las Naciones Unidas. Disponible en http://daccess-dds ny.un.org/ doc/RESOLUTION/GEN/NR0/397/59/IMG/ NR039759.pdf?OpenElement (17/6/15)

Resolución (1990). A/RES/45/199: Estrategia Internacional del Desarrollo para el Cuarto Decenio de las Naciones Unidas. Disponible en http://daccess-dds-ny.un.org/ doc/RESOLUTION/GEN/NR0/573/62/IMG/ NR057362.pdf?OpenElement (17/6/15)

Resolución (1997). A/RES/51/240: Plan de Desarrollo. Disponible en http://daccess-ddsny.un.org/doc/UNDOC/GEN/N97/774/82/ PDF/N9777482.pdf?OpenElement (17/6/15)

Torres del Moral A. (1996). Introducción al Derecho Constitucional. Madrid: Servicio de Publicaciones de la Universidad Complutense 